\title{
Interest Rate Uncertainty and the Value of Bond Call Protection
}

\section{Citation}

Bodie, Zvi, and Benjamin M. Friedman. 1978. Interest rate uncertainty and the value of bond call protection. Journal of Political Economy 86(1): 19-43.

\section{Published Version}

doi:10.1086/260645

\section{Permanent link}

http://nrs.harvard.edu/urn-3:HUL.InstRepos:4554310

\section{Terms of Use}

This article was downloaded from Harvard University's DASH repository, and is made available under the terms and conditions applicable to Other Posted Material, as set forth at http:// nrs.harvard.edu/urn-3:HUL.InstRepos:dash.current.terms-of-use\#LAA

\section{Share Your Story}

The Harvard community has made this article openly available.

Please share how this access benefits you. Submit a story.

Accessibility 


\title{
Interest Rate Uncertainty and the Value of Bond Call Protection
}

\section{Zvi Bodie}

Boston University

\section{Benjamin M. Friedman}

Harvard University

\begin{abstract}
This paper uses a model of the valuation of bonds bearing call options, together with observed market yields on callable bonds, to infer information about the uncertainty associated with interest rate expectations. A dynamic programming solution of the model simultaneously determines both the bond price and the issuer's optimal refunding strategy, given the relevant data describing the bond and the market's expectations of future interest rates. Application of the valuation model in reverse, for quarterly average data for 1969-76, generates a time series representing the uncertainty which the market associated with its expectations of future interest rates during this interval, given the then-prevailing yields on new issues of utility bonds and industrial bonds callable after 5 years and 10 years, respectively. This uncertainty, parameterized as the standard deviation of a truncated normal distribution, fluctuated between $\frac{1}{2}$ percent and $\frac{3}{4}$ percent between 1969 and early 1974, then rose to sharply higher levels from mid-1974 through mid-1975, and has fluctuated between $\frac{3}{4}$ percent and 1 percent since late 1975 .
\end{abstract}

The treatment of expectations is today one of the major loose ends of empirical economics. Economists have increasingly come to realize that expectations of future outcomes play a key role in a wide variety of

The authors are, respectively, assistant professor of economics and finance, Boston University School of Management, and associate professor of economics, Harvard University. They are grateful to Richard Cohn, Ray Fair, Robert Glauber, Peter Jones, Jay Light, John Lintner, Huston McCulloch, Franco Modigliani, Paul Wachtel, and this Journal's anonymous referees for helpful comments on a previous draft. The National Science Foundation's support of Friedman's work on this project, under grant SOC74-21027, is gratefully acknowledged.

[Journal of Political Economy, 1978, vol. 86, no. 1]

(C) 1978 by The University of Chicago. 0022-3808/78/8601-0002\$02.00. 
decision-making processes, and theoretical studies of expectations have abounded in recent years. Since most of these expectations are not subject to direct observation, however, in empirical work it is typically necessary to infer the nature of the expectations formation process indirectly. Given the difficulty of learning about the formation of expectations, any sources of independent evidence are welcome.

In recent years the corporate bond market in the United States has provided one relatively straightforward-though little exploited in the economics literature-source of information about expectations of future prices in this market, that is, about expectations of future long-term yields. Throughout the twentieth century, corporate "bonds" issued in the United States have not been pure bonds; in almost all cases the security purchased by an investor has consisted of a pure bond less an option, retained by the issuer, to call the bond at a specified price. ${ }^{1}$ Just within the past 15 years, however, the nature of this option arrangement has changed radically. Until 1958, the call option was almost always unrestricted, in theory exercisable by the issuer the very day after the initial sale of the bonds. Since the mid-1960s, the call option has almost always been restricted, exercisable only after some specified deferment period. In addition, the length of this mandatory call-option deferment in the more recently issued bonds has differed in a consistent way among the major recognized subcategories of corporate bonds; industrial bonds and utility bonds, for example, have almost always borne 10 years and 5 years, respectively, of call protection.

Several authors have presented models of the valuation of bond call options, ${ }^{2}$ acknowledging in each case the relationship between the option value and expectations of future interest rates, but (to the authors' knowledge) no one has attempted to use such a model to draw inferences about interest rate expectations on the basis of observed market prices of callable bonds. To date, the primary vehicle used to draw empirical inferences about expected interest rates has been the structure of yields on debt securities of different maturity. ${ }^{3}$

The object of this paper is to use a model for pricing bonds bearing call options, together with observed market yields on bonds with differing calloption features, to infer information about market-participants' expectations of future interest rates. In particular, unless market participants are perfectly confident of the accuracy of their expectations of future interest

\footnotetext{
1 The security is the bond less the option, because in effect the purchaser of the bond is required to write an option to the issuer, permitting the issuer to call the bond, i.e., to repay the loan.

2 See Crockett's appendix to Hess and Winn (1962), Pye (1966, 1967), Jen and Wert (1967), and Elton and Gruber (1972).

${ }^{3}$ Hicks (1939) and Lutz (1940) first developed the expectations hypothesis of the term structure of interest rates (see Nelson [1972] and Modigliani and Shiller [1973], and the references cited by these authors, for a review of recent work on this subject).
} 
rates, these expectations are equivalent to probability distributions with nonzero variances. In contrast to the term-structure literature, which draws inferences about the means of these expectations, this paper applies a call-option valuation model to market-price data so as to draw inferences about the uncertainty (variance) associated with expectations of future interest rates.

Section I summarizes the relevant institutional background, including market history and indenture mechanics, of corporate bonds bearing call options subject to deferment restrictions. Section II summarizes a dynamic programming model, developed elsewhere by the authors, which simultaneously indicates the bond issuer's optimal refunding decision and the resulting value of the callable bond. As in Pye's (1966, 1967) work, upon which this model draws, the stochastic nature of the time rate of discount is a key element of the model, ${ }^{4}$ and the discussion of the model makes explicit the role of interest rate expectations. Section II also illustrates several of the properties of this optimal decision and valuation model, especially the implications of both the mean and the variance of expectations of future interest rates, by applying the model to a few hypothetical examples. Section III applies the valuation model in reverse to draw inferences about the uncertainty associated with the market's interest rate expectations, based on the differing yields on bonds with different calloption deferment length, during 1969-76. Section IV briefly summarizes the paper's principal results and indicates several interesting possibilities for further research.

\section{Background}

Long-term corporate bonds issued in the United States are almost always callable by the issuer, with the exercise price of the call option specified in advance in the terms of the bond indenture. The call price typically provides for some premium above the bond's principal amount, with that premium varying positively with the number of years remaining to maturity at the time of exercise of the call option. One commonly used schedule of call prices, for example, begins at 100 percent of principal amount plus 1 year's coupon interest, if the bond is called within 1 year of its issue, and declines linearly to 100 percent of principal amount some few years before maturity.

Prior to 1957, the call options borne by U.S. corporate bonds were rarely restricted. Hess and Winn (1962) studied a comprehensive sample of over 1,250 high-quality industrial and utility bonds issued both publicly

\footnotetext{
${ }^{4}$ Elton and Gruber (1972) also incorporated a stochastic discount rate in their model, which is similar to Pye's. By contrast, much of the literature analyzing the refunding option has been deficient in assuming a nonstochastic discount rate (see, e.g., Kalymon [1971], Kraus [1973], and Elton and Gruber [1975]).
} 
and privately during 1926-59. Of the 572 bonds in this sample issued during 1926-43, only 21 bore restrictions deferring exercise of the call option. ${ }^{5}$ Similarly, of the 405 bonds in this sample issued during 1944-56, only 17 bore such restrictions.

In 1957, however, market practice began to change. Of the 288 bonds in Hess and Winn's sample issued during 1957-59, 100 bore restrictions deferring exercise of the call option for 5 years or more after the bond's date of issue. During the 1960s the proportion of corporate bond issues bearing such call deferments increased until, by 1968, new issues of immediately callable bonds had entirely disappeared. The market's exclusive reliance on call-protected issues has continued through the time of writing.

The U.S. corporate bond market, which has increasingly favored standardized indenture terms for public issues as a means of enhancing the bonds' ready tradability, has developed several conventions pertaining to the call features of corporate bonds. Among such standardized practices, the time length of the deferment restriction is particularly relevant to this paper's analysis. ${ }^{6}$ By convention, the market has developed two distinct deferment lengths. Industrial companies' bonds almost always bear 10 years of call protection, as do bonds issued by commercial companies, banks, and finance companies. In contrast, utility companies, which typically account for one-third to one-half of the gross market volume of new corporate bond issues, almost always issue bonds bearing only 5 years. of call protection, regardless of the prevailing yield differential between 5- and 10-year protected issues. This behavior by utility companies has reflected, in part, the attitudes of state-level utility rate commissions. Utility companies have deviated from the practice of issuing 5-year protected issues only during periods of unusual market distress, such as in the summer of 1974; Section III below comments specifically on the 1974 experience.

In the U.S. corporate bond market of recent years, therefore, the investor in new issues has been able to choose between bonds with 10 years of call protection and bonds with only 5 years of call protection. Furthermore, by moving to seasoned corporate issues, in which sizable purchases have become easier as trading activity has increased, the investor may also opt either for bonds which have less than the original 5 or 10 years of call protection or, at the other extreme, for bonds which have no formal call protection at all but which are nonetheless extremely unlikely to be called because of their low coupons. In addition, the U.S. government securities

5 In the 1926-43 part of their sample, Hess and Winn did not distinguish between bonds with no call deferment and bonds with call deferred by less than 1 year.

${ }^{6}$ With respect to the precise nature of the deferment restriction itself, two forms have evolved: nonredeemability, and nonrefundability. This paper disregards the distinction between these two forms, which has only rarely mattered operationally and has not seemed to play a significant role in investors' decisions. 
market provides bonds with substantially longer formal call protection; the call option on most long-term Treasury issues is restricted to the last 5 years before the bond's maturity date. Given this breadth of investor choice, the market inevitably prices the different securities in a way which reveals preferences for one security versus another. As Section II below shows, when two bonds differ primarily in their respective restrictions on exercise of the call option, the resulting price (yield) difference between the two is itself closely related to investors' expectations of future interest rates.

\section{The Value of Bonds Bearing Call Options ${ }^{7}$}

\section{A. A Decision and Valuation Model}

The value of a bond subject to a call option equals the value of an otherwise identical noncallable bond less the value of the call option. The value of the option in this case follows from a decision problem in which the option holder (the issuer of the bond) maximizes an objective, subject to both the specified characteristics of the call option itself and his expectations of the relevant future prices (or interest rates). At any moment of time, a bond issuer with callable bonds outstanding must decide whether or not to call the bonds. In an abstraction to a discrete-time model, the issuer must decide, at the beginning of each time period, whether to call the bonds or to leave them outstanding until the beginning of the next time period. Calling a bond at the beginning of time period $t$ implies an immediate payment of $C_{t}$, the current call price, ${ }^{8}$ while not calling the bond implies a payment of coupon $k$ at the end of the current time period $t$ and a new decision at the beginning of the subsequent time period $t+1$.

Two convenient assumptions about the behavior of the firm facilitate modeling the issuer's optimal decision, and hence the value of the bond. First, in order to abstract from considerations relating to the firm's production, sales, and investment decisions, it is useful to assume that the firm makes the call decision independently of the "revenue" side of its activities. Second, in order to have a decision criterion, it is useful to assume that the objective determining the call decision is to minimize the present discounted value of the expected stream of payments associated with the out-

${ }^{7}$ For the full development of the model summarized in this section, see Bodie and Friedman (1977). The model abstracts from the possibility of default risk as well as from any differential tax treatment of the payment of interest versus call premiums. As applied in this paper (in contrast to the development in Bodie and Friedman), the model also does not distinguish between the issuer's and investors' expectations.

${ }^{8}$ To the extent that the refunding operation involves transactions costs, such as investment bankers' fees or use of management time, $C_{t}$ includes these costs as well as the call price per se. 
standing bond (or its refinancing replacement). ${ }^{9}$ The value of a callable bond to the issuer as of the beginning of time period $t$ is therefore

$$
V_{t}=\min \left\{C_{t}, \frac{1}{1+\rho_{t}}\left[k+E_{t}\left(\tilde{V}_{t+1}\right)\right]\right\},
$$

where $\rho_{t}$ is the time rate of discount which prevails in time period $t, E_{t}(\cdot)$ indicates an expectation as of the beginning of time period $t$, and the tilde symbol recalls that $\tilde{V}_{t+1}$ is a random variable as of the beginning of time period $t$. The appearance of $\tilde{V}_{t+1}$ in one of the two alternative expressions for $V_{t}$ immediately suggests a recursion relation requiring solution by dynamic programming.

The importance of the issuer's expectations of future yields emerges clearly in the explicit evaluation of the expectation on the right-hand side of (1):

$$
\begin{aligned}
E_{t}\left(\tilde{V}_{t+1}\right)= & { }_{t} P_{t+1} \cdot C_{t+1}+\left(1-{ }_{t} P_{t+1}\right) \\
& \cdot E_{t}\left\{\frac{1}{1+\tilde{\rho}_{t+1}}\left[k+E_{t+1}\left(\tilde{V}_{t+2}\right)\right]\right\},
\end{aligned}
$$

where ${ }_{t} P_{t+1}$ is the probability, assessed as of the beginning of time period $t$, that the optimal decision at the beginning of time period $t+1$ will be to refund the bond. Hence the expectation $E_{t}\left(\tilde{V}_{t+1}\right)$ equals the linear combination of the known call price $C_{t+1}$, premultiplied by probability ${ }_{t} P_{t+1}$, and the conditional expectation of the value of the bond in the event that the optimal decision at the beginning of time period $t+1$ is not to refund it, premultiplied by probability $\left(1-{ }_{t} P_{t+1}\right)$. One element of that conditional expectation is in turn $E_{t+1}\left(\tilde{V}_{t+2}\right)$-the expectation, as of the beginning of time period $t+1$, of the value of the bond at the beginning of yet the next time period, once again conditional on the issuer's optimal decision being not to refund the bond in either of time periods $t$ or $t+1$. The explicit evaluation of that conditional expectation, in turn, continues the sequence analogously.

A major problem in empirically implementing any such model of the issuer's optimal refunding decision is identifying the discounting rate $\rho .{ }^{10}$

${ }^{9}$ Other objectives, perhaps incorporating risk aversion, also would be suitable. The only requirement, which follows from the use of dynamic programming to solve the model, is that the objective function exhibit the intertemporal separability (additivity) property; for reference, see Bellman (1957) and Bellman and Dreyfus (1962). In conjunction with a further assumption extending the present discounted value criterion to other aspects of the issuer's behavior, this objective is consistent with maximization of stockholders' wealth.

${ }^{10}$ A substantial part of the literature of the optimal refunding decision has focused on precisely the question of what is the appropriate discount rate to use in this calculation (see, e.g., Ofer and Taggart [1977] and the references cited therein). 
In a purely theoretical abstraction, the notion of $\rho$ seems clear enough; it is an "opportunity cost" discount factor reflecting the cost of alternative sources of financing and the risk-adjusted return on the firm's assets-both of which must be equal in equilibrium. In practice, however, different forms of financing may have different perceived costs at any given time, and market imperfections may dominate the determination of asset returns. Furthermore, quantifying the relevant perceived risk-adjusted returns is itself far from straightforward.

The primary reason why identifying the relevant discount rate for the refunding decision is so difficult is that in practice, contrary to the simplifying assumption made above, firms are typically making a wide variety of different decisions simultaneously-deciding what investment opportunities to pursue, what size liquid asset position constitutes an adequate safety margin, how to structure their liabilities, etc. A further assumption which cuts through this complex simultaneity is that the refunding decision with respect to outstanding long-term securities presupposes no change in the firm's liability structure in the sense of term to maturity (apart from call features). While this assumption does introduce some possibility for misunderstanding the issuer's refunding decision problem, it is probably not too far off the mark for practical purposes, since most issuers do in fact consider a refunding situation in the somewhat limited context of replacing outstanding long-term bonds with a new issue of long-term bonds (presumably bearing a lower coupon). ${ }^{11}$ Furthermore, for operational purposes the primary question is whether this simplifying assumption introduces more or less possibility for misunderstanding than does an alternative assumption identifying the relevant discount rate $\rho$ with some specific observable variable.

Optimal refunding decision model (1) relies on an implicit two-fork decision tree approach in which, at the beginning of any time period $t$, the "terminal" (refund) fork is the immediate payment of call price $C_{t}$ while the "continuing" (do not refund) fork is the payment of coupon $k$ at the end of the time period (i.e., the beginning of the next time period) and a new decision then. If the issuer presupposes financing of the refunding by a new issue of long-term bonds, then the "terminal" fork is no longer an end point, and its value is not simply the call price but rather the stream of future payments of interest and principal on the newly issued security. It is therefore necessary to consider the coupon rate $k_{t}$ which, as of the beginning of time period $t$, is the market yield on new issues of the firm's long-term bonds. Furthermore, since new issues of immediately callable long-term bonds do not exist in the U.S. markets, it is appropriate to con-

${ }^{11}$ More precisely, issuers most often use a refunding situation to extend somewhat the maturity of their outstanding debt; Elton and Gruber's generalization of Pye's model focuses on this point. 
sider $k_{t}$ as the coupon rate on a new issue of long-term bonds bearing call options subject to deferral for some interval. ${ }^{12}$

In the restricted context of a predetermined liability maturity structure, then, the issuer's refunding decision involves a comparison of the present value of two alternative streams of payments. One, as in (1), is the payment of coupon $k$ for all time periods until the bond is called, with a new refunding decision possible in each successive time period. The other is the immediate payment of call price $C_{t}$, which requires simultaneously issuing a new bond in the amount of $C_{t}$, and subsequent payment of the new coupon $k_{t}$ for at least $D$ time periods (where $D$ is the length of the deferment period on the new bond's call option), with refunding decisions possible only in later time periods. The fixed-maturity analog to the issuer's refunding decision (1) is therefore

$$
V_{t}=\min \left\{R_{t}, \frac{1}{1+\rho_{t}}\left[k+E_{t}\left(\tilde{V}_{t+1}\right)\right]\right\},
$$

where the value of the stream of payments associated with the refinancing bond is ${ }^{13}$

$$
\begin{aligned}
R_{t}=\frac{C_{t}}{1+\rho_{t}}\left(k _ { t } \left\{1+\sum_{\tau=t+1}^{T}\right.\right. & {\left.\left[\prod_{s=t+1}^{\tau} \int_{0}^{\infty} \frac{1}{1+\tilde{\rho}_{s}} f_{t}\left(\tilde{\rho}_{s}\right) d \rho\right]\right\} } \\
& \left.+\prod_{\tau=t+1}^{T} \int_{0}^{\infty} \frac{1}{1+\tilde{\rho}_{\tau}} f_{t}\left(\tilde{\rho}_{\tau}\right) d \rho\right)
\end{aligned}
$$

$T$ is the time period at the end of which the currently outstanding callable bond (and hence, by assumption, the refinancing bond also) matures; and $f_{t}\left(\tilde{\rho}_{\tau}\right), \tau=t+1, \ldots, T$, are independent probability density func-

12 As the discussion of Section I points out, U.S. issuers of long-term corporate bonds almost always issue bonds bearing call options deferred for either 5 or 10 years, depending on the business of the issuer. Issuers refunding bonds which originally bore 5-year call deferments will typically issue new bonds bearing 5-year deferments. Issuers refunding bonds which originally bore 10-year deferments will typically issue new bonds bearing 10-year deferments.

13 This simplified expression overstates $R_{t}$ in that it does not take account of the possibility of subsequently calling the refinancing bond before maturity. The correct expression is

$$
\begin{aligned}
R_{t}=\frac{C_{t}}{1+\rho_{t}}\left(k _ { t } \left\{1+\sum_{\tau=t+1}^{t+D}\left[\prod_{s=t+1}^{\tau} \int_{0}^{\infty}\right.\right.\right. & \left.\left.\frac{1}{1+\tilde{\rho}_{s}} f_{t}\left(\tilde{\rho}_{s}\right) d \rho\right]\right\} \\
& \left.+E_{t+D}\left(\tilde{R}_{t+D+1}\right) \cdot \prod_{\tau=t+1}^{t+D} \int_{0}^{\infty} \frac{1}{1+\tilde{\rho}_{\tau}} f_{t}\left(\tilde{\rho}_{\tau}\right) d \rho\right),
\end{aligned}
$$

where $E_{t+D}\left(\tilde{R}_{t+D+1}\right)$ follows from a further backward induction solution analogous to that shown below except using $k_{t}$ in place of $k$, and expression (7) below is likewise altered (see Bodie and Friedman [1977]). Hence the model is in general able to accommodate an entire series of potential refundings, as would be the case for $D$ small relative to $T$. The possibility of multiple refundings, however, means that the computational requirements of the solution no longer increase only linearly with $T$. 
tions describing the issuer's expectations, as of time period $t$, about the (unknown) future path of the stochastic discount rate $\tilde{\rho}_{\tau^{\cdot}}{ }^{14}$

The issuer's fixed-maturity refunding decision therefore involves two distinct sets of interest rate expectations, as is clear from considering the conditional expectation on the right-hand side of $(3),{ }^{15}$

$$
E_{t}\left(\tilde{V}_{t+1}\right)={ }_{t} P_{t+1} \cdot E_{t}\left(\tilde{R}_{t+1}\right)+\frac{1-{ }_{t} P_{t+1}}{1+\rho_{t}}\left[k+E_{t+1}\left(\tilde{V}_{t+2}\right)\right] .
$$

As of the beginning of time period $t, k_{t}$ is known, but $\tilde{k}_{t+1}$ is not. Hence $\widetilde{R}_{t+1}$ is random, as of the beginning of time period $t$, because of uncertainty associated not only with future $\tilde{\rho}_{\tau}, \tau=t+1, \ldots, T$, but also with the future coupon rate $\tilde{k}_{t+1}$. The reason why expectations of future coupon rates enter the problem is the "lock-in" feature associated with the noncallability (or call-option deferment) of the refinancing bonds. Refinancing with immediately callable bonds is not possible, and refinancing with noncallable bonds requires the issuer to pay coupon $k_{t}$ in every subsequent time period, regardless of the potential emergence of even lower new-issue coupon rates later on. ${ }^{16}$ Even if an issuer can refinance the outstanding $k$-coupon bonds by issuing new bonds with some coupon $k_{t}$ which is enough lower than $k$ to warrant paying the current call price, therefore, he may gain even more by waiting to refinance, say $s$ time periods later, at the then-prevailing coupon rate $\tilde{k}_{t+s}$ which may be even less than $k_{t}$. It is this feature of the problem which gives the variance, or volatility, of future long-term new-issue yields an added importance for the optimal refunding decision and the resulting value of the callable bond. Even if the issuer expects the long-term new-issue yield to be high in the future on average, if he expects this yield to be volatile he may value greatly the opportunity to refund at precisely the time when the yield has fallen below his expectation of its long-term average.

\footnotetext{
14 No general solution exists for the refunding decision problem when expectations of the stochastic discount rate are state dependent. To solve this problem, therefore, it is necessary to specify a unique stochastic process which the issuer assumes to generate the future $\tilde{\rho}_{t}$, so that the resulting solution depends on the particular stochastic process chosen. Pye (1966) dealt with this problem by assuming that the discount rate followed a first-order Markov process, with a small number of possible states. and using either estimated values or arbitrarily assigned values for the elements of the transition matrix. Black and Scholes (1973) and Merton (1974) have developed a more general methodology which could be used to implement the stochastic process approach to the issuer's decision problem with state-dependent expectations. The state-independence assumption introduced above renders the problem solvable by straightforward dynamic programming techniques while still permitting a general form for the density functions $f_{t}\left(\tilde{\rho}_{\tau}\right)$.

15 Once again, this expectation is conditional on the bond not being called as of the beginning of time period $t$.

${ }_{16}$ The problem is therefore similar to the optimal one-time sale of an asset in the context of an uncertain stream of bids (see, e.g., Karlin's [1962] highly instructive treatment of that question).
} 
In complete form, therefore, the solution to the fixed-maturity refunding decision problem leads to a backward succession, from time period $T$, of expressions involving integration over two sets of density functions-one for the discount rate and one for the coupon rate. Expectations about these two interest rates, however, are unlikely to be independent. A useful simplification which avoids altogether the need for two different sets of integrals is simply to assume that expectations about one rate are one-for-one equivalent to expectations about the other, that is,

$$
f_{t}\left(\tilde{\rho}_{t+s}\right)=f_{t}\left[g_{t+s}\left(\tilde{k}_{t+s}\right)\right], f_{t}^{\prime}\left(\tilde{k}_{t+s}\right)=f_{t}^{\prime}\left[g_{t+s}^{-1}\left(\tilde{\rho}_{t+s}\right)\right], s>0,
$$

for some nonstochastic transformation $g_{t+s}(\cdot)$ for each time period $t+s$. Under this covariation assumption it is possible to restate the issuer's refunding decision problem in terms of expectations of future new-issue yields on long-term (noncallable) bonds, so that (4) becomes

$$
\begin{aligned}
R_{t}=\frac{C_{t}}{1+g_{t}\left(k_{t}\right)}\left(k _ { t } \left\{1+\sum_{\tau=t+1}^{T}\right.\right. & {\left.\left[\prod_{s=t+1}^{\tau} \int_{0}^{\infty} \frac{1}{1+g_{s}\left(\tilde{k}_{s}\right)} f_{t}^{\prime}\left(\tilde{k}_{s}\right) d k\right]\right\} } \\
& \left.+\prod_{\tau=t+1}^{T} \int_{0}^{\infty} \frac{1}{1+g_{\tau}\left(\tilde{k}_{\tau}\right)} f_{t}^{\prime}\left(\tilde{k}_{\tau}\right) d k\right),
\end{aligned}
$$

while the analogous expectation on the right-hand side of (5) becomes

$$
\begin{aligned}
E_{t}\left(\tilde{R}_{t+1}\right)= & C_{t+1} \int_{0}^{\infty} \frac{1}{1+g_{t+1}\left(\tilde{k}_{t+1}\right)} \\
& \cdot\left(\tilde{k}_{t+1}\left\{1+\sum_{\tau=t+2}^{T}\left[\prod_{s=t+2}^{\tau} \int_{0}^{\infty} \frac{1}{1+g_{s}\left(\tilde{k}_{s}\right)} f_{t}^{\prime}\left(\tilde{k}_{s}\right) d k\right]\right\}\right. \\
& \left.+\prod_{\tau=t+2}^{T} \int_{0}^{\infty} \frac{1}{1+g_{\tau}\left(\tilde{k}_{\tau}\right)} f_{t}^{\prime}\left(\tilde{k}_{\tau}\right) d k\right) f_{t}^{\prime}\left(\tilde{k}_{t+1}\right) d k .
\end{aligned}
$$

For a conventional bond, the terminal condition which anchors the dynamic programming solution to the optimal refunding problem as posed in (3), (5), (7), and (8) is simply the statement of the bond's par-value maturity property,

$$
V_{T+1}=1 \text {. }
$$

The solution follows as a series of critical values $k_{T}^{*}, k_{T-1}^{*}, \ldots, k_{D+1}^{*}$, such that the optimal decision is to call the bond in period $t$ if and only if $k_{t}<k_{t}^{*}$.

At the beginning of time period $T$, the problem is simply

$$
V_{T}=\min \left\{R_{T}, \frac{1}{1+g_{T}\left(k_{T}\right)}(k+1)\right\},
$$


where, because $k_{T}$ is known, $R_{T}$ is the nonrandom

$$
R_{T}=\frac{C_{T}}{1+g_{T}\left(k_{T}\right)}\left(k_{T}+1\right) .
$$

The critical value $k_{T}^{*}$ follows as the new-issue rate which equates the two alternatives within the right-hand side of $(10)$, and the optimal refunding decision is to call the bond or not according to $k_{T} \lessgtr k_{T}^{*}$. If $C_{T}=1$, then $k_{T}^{*}=k_{T}$, and the final-period refunding decision simply involves a comparison of the current (one-period) borrowing rate with the outstanding bond's coupon. ${ }^{17}$

For each subsequent time period $t, t=T-1, \ldots, \mathrm{D}+1$ (going backward), the problem is just (3), where $R_{t}$ is as in (7),

$$
\begin{aligned}
E_{t}\left(\tilde{V}_{t+1}\right)= & \int_{0}^{k_{t+1}^{*}} \tilde{R}_{t+1} f_{t}^{\prime}\left(\tilde{k}_{t+1}\right) d k \\
& +\left[k+E_{t+1}\left(\tilde{V}_{t+2}\right)\right] \int_{k_{t+1}^{*}}^{\infty} \frac{1}{1+g_{t+1}\left(\tilde{k}_{t+1}\right)} f_{t}^{\prime}\left(\tilde{k}_{t+1}\right) d k,
\end{aligned}
$$

and the critical value $k_{t}^{*}$ follows as the $(T-t+1)$-period new-issue rate which equates the two alternatives within the right-hand side of (3). Following this procedure backward to the solution for $E_{D}\left(\tilde{V}_{D+1}\right)$, and then using the simple discounting procedure

where

$$
V_{t}=\frac{1}{1+g_{t}\left(k_{t}\right)}\left[k+E_{t}\left(\tilde{V}_{t+1}\right)\right]
$$

$$
E_{t}\left(\tilde{V}_{t+1}\right)=\left[k+E_{t+1}\left(\tilde{V}_{t+2}\right)\right] \int_{0}^{\infty} \frac{1}{1+g_{t+1}\left(\tilde{k}_{t+1}\right)} f_{t}^{\prime}\left(\tilde{k}_{t+1}\right) d k
$$

for earlier time periods $1 \leq t \leq D$ (for which there is no call option) finally yields the new-issue value of the deferred callable bond, $V_{1}$.

\section{B. Illustrations}

A few hypothetical examples may serve to illustrate some of the pertinent properties of the solutions yielded by the bond valuation and optimal refunding decision solution procedures developed above.

${ }^{17}$ For the later periods of the outstanding bond's term (i.e., the first periods treated in the backward induction), the term to maturity of the refinancing bond to be issued is very short under the fixed-maturity assumption. For the limiting case of the final time period $T$ as in (10) and (11), e.g., $k_{T}$ is a one-period borrowing rate, so that the discounting rate is $g_{T}\left(k_{T}\right)=k_{T}$. For discount rates of the order of those in the numerical examples presented below, however, any term-structure implications of this aspect of the fixed-maturity assumption in far-off time periods have only very small effects on the resulting calculations for current refunding decisions and valuations. 
Consider, for example, a 25-year bond with a coupon of 8 percent per annum payable semiannually. In addition, suppose that the relevant discounting rate is also 8 percent per annum and that everyone expects the market yield to continue to be 8 percent per annum. If the bond is noncallable, then the initial value is simply $100 .{ }^{18}$ Since the expected market yield is 8 percent per annum for the next 25 years, the bond's expected price in any future period until maturity is also 100 .

If the same 25-year 8 percent bond is callable, however, and if people believe that the market yield may fall below 8 percent per annum at some point during the bond's 25-year life (i.e., there is some nonzero variance associated with the 8 percent expectation), then neither the initial value nor the expected price in any future time period before maturity equals 100. The income stream generated by this bond (and its replacement, in the event of refunding) will under no circumstances be greater than that of the initial 8 percent coupon rate. Because of the possibility of refunding, which in turn depends upon future interest rates and expectations thereof, this income stream may be less than that of the initial 8 percent coupon rate. Given a discounting factor of 8 percent, therefore, the bond's price will always be strictly less than 100 , unless interest rate expectations are such as to preclude the possibility of refunding.

Nevertheless, in the United States as well as in most other countries, new long-term bonds are typically issued at or near 100 even when they bear call options. Since a coupon rate equal to the mean $E\left(\tilde{k}_{t}\right)$ of stationary expectations of future market discount rates results in callable bond prices less than 100 , some coupon rate greater than this mean is necessary to make the callable bond worth 100 at the time of issue. For any given set of stationary expectations of future interest rates, the amount by which the coupon rate must exceed the fixed mean $E\left(\tilde{k}_{t}\right)$ depends not only upon the bond's call features but also, following the model developed above, upon the higher moments of the density functions describing interest rate expectations.

Figure 1 summarizes the results of applying the optimal refunding decision and bond valuation model to three hypothetical bonds. All three are 25-year bonds with coupons payable semiannually and with call prices which decline linearly from 100 plus 1 year's coupon interest in the first half year to 100 in the final half year of the bond's term to maturity. The model assumes as above that, in the event of refunding, the refinancing will leave unchanged the maturity structure of the issuer's liabilities; furthermore, to simplify the calculations, these examples also assume that the refinancing bond is to be noncallable until maturity.

Following the structure of the model, it is necessary to specify the probability density functions $f^{\prime}(\cdot)$ for the relevant interest rate expectations.

${ }^{18}$ N. 23 below qualifies this statement. 

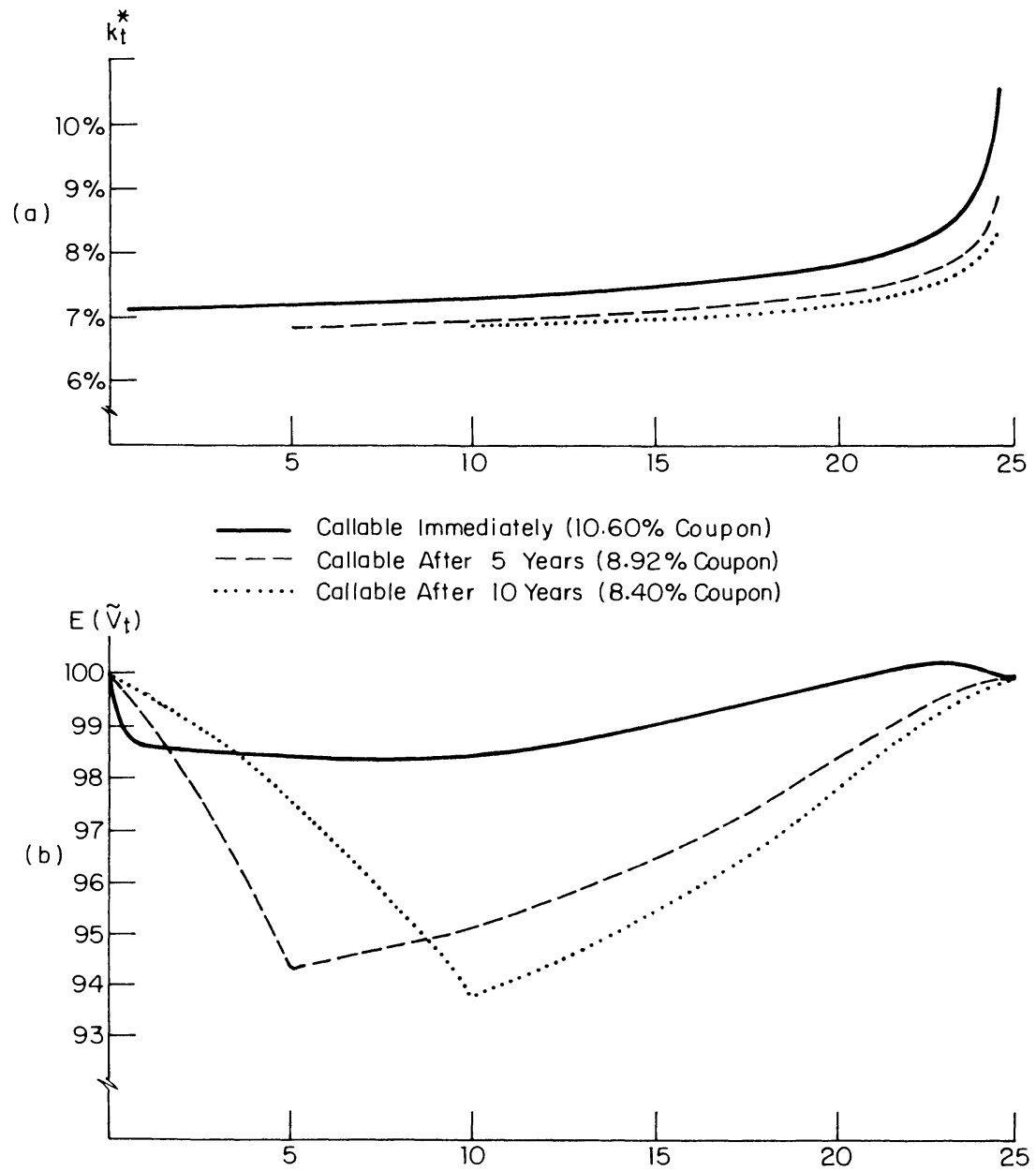

FIG. 1.-Critical refunding yields and expected prices for 25-year bonds issued at par

The key parameterizing assumptions underlying these solutions are that expectations of future coupon interest rates $f^{\prime}\left(\tilde{k}_{t}\right), t=2, \ldots, T(=25:$ II $)$ are characterized by a truncated normal distribution with mean 8 percent and standard deviation 1 percent, ${ }^{19}$ and that the relationship between discounting factor $\rho_{t}$ and coupon rate $k_{t}$ as in (6) is simply $\rho_{t}=k_{t}$, $t=1, \ldots, T$.

The first example considered is an immediately callable 10.60 percent bond. The solid line in panel $a$ of figure 1 plots, for each half-year period, the critical refunding yield $k_{t}^{*}$ which follows as the $(T-t+1)$-period

19 The normal distribution is truncated so as to preclude expectations of negative nominal interest rates. 
new-issue rate which equates the two alternatives within the right-hand side of (3). The issuer's optimal decision, at the beginning of time period $t$, is to refund the outstanding bond if and only if the then-prevailing newissue rate is below the corresponding critical value. The monotonically increasing series of critical values, which rises to 10.60 percent only in the final half-year, illustrates clearly the implication of a call-protected refunding bond. In particular, it is not optimal to refund the outstanding bond at every coupon rate below 10.60 percent (the bond's own coupon), even though doing so would lead to an interest saving, or even at every coupon rate below 8 percent (the mean expected future new-issue rate). Unless the current new-issue rate is below the critical value, the present discounted value of the interest saving achieved by refunding at that rate is smaller than the present discounted value of the expected interest saving from waiting to refund in some later time period. ${ }^{20}$ Given the assumed constant mean and nonzero variance of the distributions describing expectations of future interest rates, the earlier is the time period $t$, the lower the coupon rate on the refinancing bond must be to justify refunding.

The solid line in panel $b$ of figure 1 plots, for the same half-year periods, the price $V_{t}$ expected to prevail at the beginning of the period for this immediately callable 25-year 10.60 percent bond. As the intercept indicates, 10.60 percent is precisely the coupon rate necessary to render the bond's new-issue price equal to 100, given the bond's call provisions and the assumed expectations of future interest rates. ${ }^{21}$ The bond's expected price declines for 7 years (with the largest decline coming after the first half-year, when the implicit one-period call deferment expires), then rises until shortly before the bond's maturity, and finally declines back to 100 .

The broken and dotted lines in figure 1 plot the analogous solution values for a 25 -year 8.92 percent bond callable after 5 years and a 25 -year 8.40 percent bond callable after 10 years, respectively. Because of the series of certain coupon payments guaranteed by their respective call deferments, the coupon rates necessary to render these bonds' new-issue prices equal to 100 are less than for the immediately callable bond, and the 10 year call-protected bond requires a lower coupon rate for this purpose than does the 5-year call-protected bond.

The two call-protected bonds' respective critical refunding yields, which are defined only for time periods after the expiration of their call deferments, again rise monotonically to equal the respective coupon rates in the final half-year of the bonds' term to maturity. The expected price

\footnotetext{
20 Note that $C_{t}>100$ provides yet another reason, apart from interest rate expectations, why it may not be optimal to refund at $k_{t}<10.60$ percent. The effect of a declining call price, so that $C_{t+\tau}<C_{t}$, could be to make it optimal to wait to refund even if $k_{t+\tau} \geq k_{t}$.

${ }_{21}$ The value of this bond's call option is simply equal to 27.90 , the difference between the callable bond's new-issue price and the price (127.90) at which a noncallable 10.60 percent per annum bond would sell given the assumed expectations.
} 
TABLE 1

Coupon Rates Required for Par New-Issue Price for Callable and Noncallable 25-YEAR BONDS $(0)$

\begin{tabular}{ccccc}
\hline \hline & $\begin{array}{c}\text { Immediately } \\
\text { Callable }\end{array}$ & $\begin{array}{c}\text { Callable } \\
\text { after } \\
5 \text { Years }\end{array}$ & $\begin{array}{c}\text { Callable } \\
\text { after } \\
\text { 10 Years }\end{array}$ & Noncallable \\
\hline 0.2 & 8.00 & 8.00 & 8.00 & 8.00 \\
0.5 & 8.48 & 8.25 & 8.12 & 8.00 \\
1.0 & 10.60 & 8.92 & 8.40 & 8.00 \\
1.5 & 13.18 & 9.65 & 8.70 & 7.99 \\
2.0 & 16.00 & 10.40 & 9.00 & 7.98 \\
2.5 & 19.03 & 11.14 & 9.30 & 7.97 \\
\hline
\end{tabular}

Note.-Assumptions: $E\left(\tilde{k}_{t}\right)=8 \%$ \% $\rho_{t}=k_{t}$, all $t$.

series for the 5- and 10-year call-protected bonds decline monotonically until the respective bonds become callable and then rise monotonically until the bonds' maturity. Because the three bonds illustrated in figure 1 each bear different coupons, their expected price series differ throughout. In particular, since it has the lowest coupon (8.40 percent), the price of the 10 -year call-protected bond falls to the lowest level of any of the three, and the different price series never overlap except at the time of issue and at maturity.

In the context of the application of the model to market data in Section III below, it is useful to consider explicitly the dependence of the results in these three hypothetical examples on the assumed 1 percent standard deviation associated with expectations of future interest rates. Table 1 shows the relationship between the assumed standard deviation value and the coupon rate necessary to render the bond's new-issue price equal to 100 , for four examples of 25-year bonds: immediately callable bonds (i.e., bonds callable after the first half-year), bonds callable after 5 years, bonds callable after 10 years, and noncallable bonds. ${ }^{22}$ For a given set of call provisions (except for the noncallable bond), ${ }^{23}$ the greater is the standard deviation, the greater must the bond's coupon be to render the new-issue price equal to 100. Conversely, for given standard deviation, the earlier the bond is callable the greater must the bond's coupon be to render the new-issue price equal to 100 .

22 The remaining assumptions underlying the solution values presented in table 1 are the same as those used in fig. 1, including flat, normally distributed expectations with $E\left(\tilde{k}_{t}\right)=8$ percent for all $t$ and truncated so as to preclude expectations of negative nominal interest rates.

${ }^{23}$ Because $E\left(1 / 1+\tilde{k}_{t}\right)>\left[1 / 1+E\left(\tilde{k}_{t}\right)\right]$ for $\left(\tilde{k}_{t}\right)>0$ (Jensen's inequality), there is always a small effect in the opposite direction, i.e., requiring a lower coupon rate as $\sigma\left(\tilde{k}_{t}\right)$ becomes larger. For callable bonds, the effect of $\sigma\left(\tilde{k}_{t}\right)>0$ on the valuation of the call option predominates. For noncallable bonds, the smaller (opposite) effect stands alone. As the "noncallable" column of table 1 indicates, however, this effect is quantitatively very small for normally distributed interest rate expectations. 


\section{Inferring Interest Rate Uncertainty from Callable Bond Yields}

The valuation and optimal refunding decision model developed in Section II makes explicit the role which the uncertainty associated with expectations of future interest rates plays in callable bond valuation. If the market prices callable bonds "correctly" (i.e., according to the valuation model), then it is possible to apply the model to observed market yield data, to infer from actually prevailing bond yields the uncertainty associated with the market's expectations of future yields. ${ }^{24}$

In principle it is possible to apply the valuation model to market data for new issues or seasoned issues, to corporate bonds or government bonds, or to bonds issued by borrowers of high-quality or low-quality creditworthiness-as long as the bonds in question have call options with known deferments. In practice, since knowledge about the bond market is not sufficient to warrant much confidence in procedures for adjusting bond yields (or prices) to allow for various kinds of heterogeneity, it is preferable to focus sharply on the impact of expectations on valuation of the call option by restricting the analysis to a group of bonds which are as homogeneous as possible in all respects other than the nature of the call option itself. Since U.S. government bonds typically have call options which are restricted until the last few years of the bond's term to maturity, whereas corporate bonds' call options are deferred for 10 or fewer years, corporate bonds seem better suited to the object of this analysis. ${ }^{25}$ In addition, greater trading activity renders the market for new issues of corporate bonds a more reliable yield indicator than the market for seasoned corporate issues, and seasoned bond indices also suffer from statistical problems due to factors such as coupon bias. Hence the empirical analysis in this paper relies on new-issue yields in the corporate bond market.

As the discussion in Section I points out, since the late 1960s virtually all new issues of U.S. corporate bonds have borne call options with deferments of either 5 years or 10 years, depending upon the business of the issuing company. Furthermore, corporate bonds are typically issued at

24 It is appropriate to point out once again the simplifications introduced in Section II, including the discrete-time framework, the absence of risk aversion, the noncallability of the refinancing bond, the normally distributed state-independent interest rate expectations, and the identity of issuers' and investors' expectations. In addition, as is usual in the interest rate literature, this analysis does not consider the aggregation problems implicit in the fact that, unless preferences are homogeneous, the market-clearing price or yield represents a point of indifference curve tangency only for some (possibly null) subset of traders.

25 Two other factors render government bonds less appropriate than corporate bonds for the purposes of this analysis. First, the primary motivation for government bond calls during the final 5-year period is usually simply to smooth the refunding process rather than refund the entire issue at maturity. Second, even if the purpose of government bond calls were interest minimization, most callable U.S. government bonds have recently traded at low prices, so that the likelihood of such a call would have appeared very small anyway. 
prices at or near par. Not surprisingly, in light of the valuation model developed in Section II, utility bonds, which become callable after 5 years, typically have greater coupons (and therefore greater new-issue yields) than industrial bonds, which become callable only after 10 years. This yield differential, or "spread," varies substantially over time. The object of the analysis here, therefore, is to apply the valuation model in reverse to infer the expectations of future interest rates which would have led the market to associate with long-term utility and industrial bonds that newissue yield differential which actually prevailed at any given time.

So as further to focus even more precisely on securities which are as comparable as possible in every respect other than the provisions of the call option, this analysis deals only with bonds rated "Aa" by Moody's Investors Service. The Aa, or "investment grade," creditworthiness category is that group which typically has the largest number of sizable issues that are broadly distributed and actively traded. As the discussion below indicates, bond issues are somewhat heterogeneous even within the Aarated category, but more finely graded classifications have appeared only recently.

The broken and dotted lines in panel $a$ of figure 2 plot the quarterly average values of the Salomon Brothers monthly estimated percentage yields on new issues of Aa-rated long-term utility bonds and industrial bonds, respectively, for 1969-76. The broken-dotted line in panel $b$ of figure 2 plots, for the same 32 quarters, the quarterly average spread between these two new-issue yields. ${ }^{26}$

These data themselves require some specific comment at the outset. The Salomon Brothers yield series are not observed yields on actual new issues of bonds but are, instead, one securities firm's estimates of the yield which a new issue of each particular category of bonds would have borne, had it been issued on the business day closest to the first of each month. The choice of 1969 as the starting date of the sample represents the earliest availability of the industrial yield series; nevertheless, even if both relevant yield series were available for the period before 1969, it would still be necessary to restrict the sample period used here to the recent years in which utility bonds and industrial bonds have conventionally borne call options deferred for 5 years and 10 years, respectively. ${ }^{27}$ The use of these

26 The Salomon Brothers yield estimates, as published in An Analytical Record of Yields and Yield Spreads, refer to the beginning of each month; the quarterly averages used here are constructed from the beginning-of-month data and centered on the midpoint of each quarter. The yield spread in panel $b$ of fig. 2 is measured in basis points, i.e., 0.01 of a percentage point.

27 The utility yield is available from the 1950s onward; but, as the discussion of Section I explains, issues in the early years were immediately callable. One complicating factor which leads to some ambiguity is that, during a brief interval in late 1974 and early 1975, a number of utility companies issued bonds bearing call options deferred for 10 years (see the discussion below). 
particular estimated yield series, as opposed to series based on observed yields of actual new issues, has both advantages and disadvantages. The primary disadvantage is simply the fact that any one firm's judgment does not necessarily reflect the full set of market expectations and preferences which are the proper object of this inquiry. The firm which prepared the series presumably made its best possible effort to estimate the state of the market, taking into account the actual yields of recent new issues, but any one market participant may at times misjudge the true state of the various forces influencing the market's behavior. The key advantages of using the estimated new-issue yield series are, first, that they are available on a consistent timing basis throughout the sample period ${ }^{28}$ and, second, that they represent estimated yields for standard size issues of standard Aa creditworthiness with no unusual complicating circumstances. ${ }^{29}$

It is realistic to assume that the bonds described in these estimated yield series would have been issued approximately at par, so that the indicated yields correspond to coupon rates as in the illustrations presented in figure 1 and table 1. Following the bond valuation model of Section II, the observed coupon rates would have been sufficient to render the callable bonds' respective new-issue prices equal to 100 only under specific conditions describing the then-prevailing expectations of future interest rates. In particular, again assuming expectations characterized by truncated normal distributions, for any given mean of expected future interest rates

28 Especially for industrial bonds, occasional long gaps in the new-issue calendar (such as in 1972 and 1973) imply that yield series based on observed new-issue yields would require substantial interpolation relying on little basis. Inconsistencies of intramonth timing of issues would create an additional problem inherent in using either an industrial or a utility series based on observed new issue yields. Even in months in which Aa-rated long-term new issues of both industrial and utility bonds occurred, so that there is no gap in either actual yield series, there may have been only one or two issues of either kind of bonds. Unless the industrial and utility issues coincided in timing, therefore, the difference between the observed new issue yields properly represented a true yield differential, in the sense required here, only on the unlikely assumption of no movement of overall yields during the month. The Salomon Brothers estimated yield series represent regular first-of-the-month judgments for every month and therefore avoid the problems due to gaps and intramonth timing inconsistencies in the new issue calendar.

29 Although the use of yields on only Aa-rated bonds represents some effort to staildardize for perceived creditworthiness of the issuing company, all issuers within the Aa class are hardly homogeneous. The yield differential between the long-term bonds of a "weak" Aa credit and those of a "strong" Aa credit is typically about 25 basis points, and at times it may be substantially greater. Given the small number of new issues, a monthly yield series based on observed yields of actual new issues would therefore be subject to fluctuation due not to market conditions but rather to the happenstance of whether the particular company or companies issuing bonds in any given month were deemed more or less creditworthy than the average for their rating class. In addition, particular characteristics of specific issues may also influence observed new issue yields; an unusually large issue, e.g., often bears a somewhat higher yield than a comparable issue of average size. The Salomon Brothers estimated yield series, which represent estimates for a standard size issue of a standard Aa-rated company, also avoid these problems of specific-issue heterogeneity. 

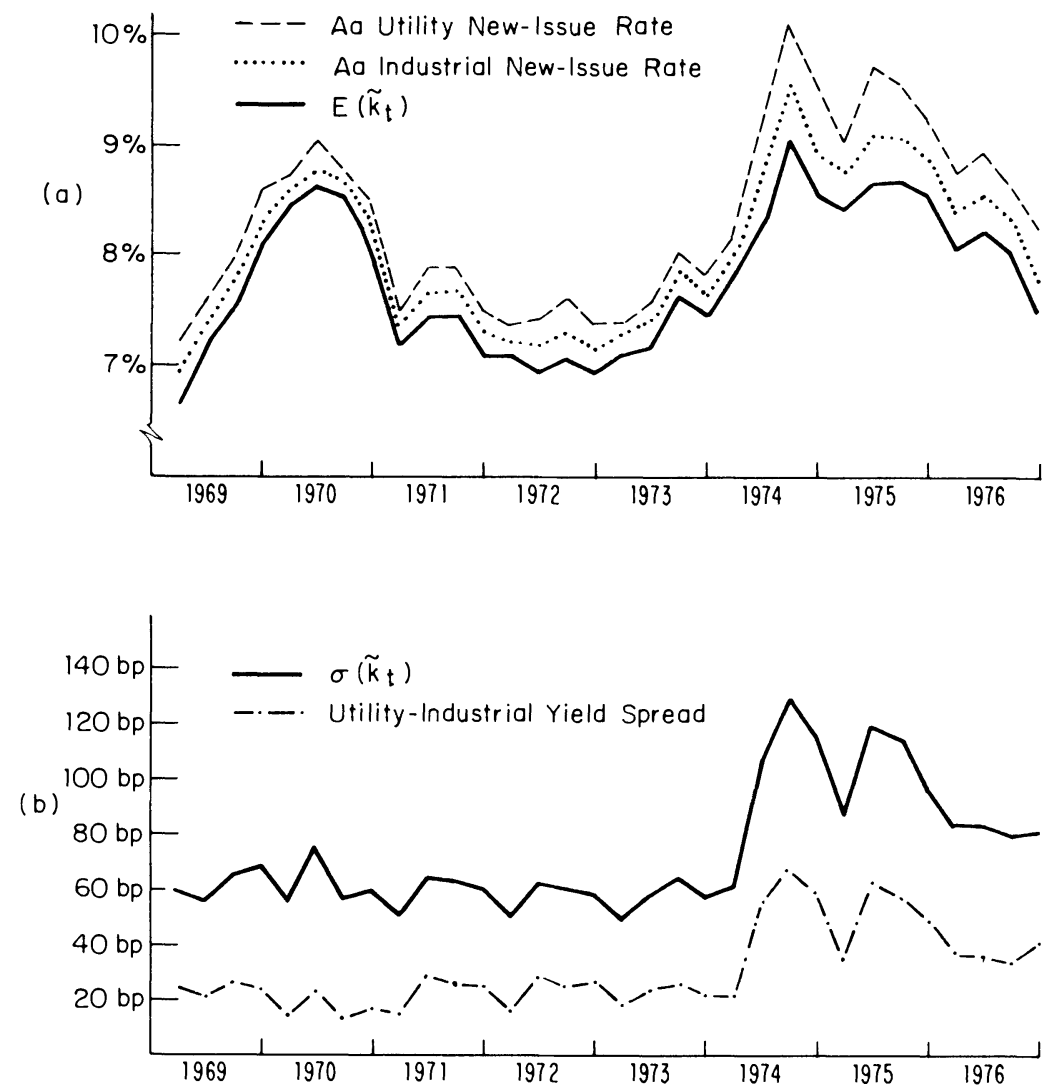

FIG. 2.-Yield and yield spread data and solution values for interest rate uncertainty

there is a unique standard deviation for which a given coupon rate (greater than the mean) renders the bond's new-issue price equal to 100 .

What makes this problem somewhat difficult is that the relevant future interest rate which is equivalent to the discounting factor $\rho_{t}$ in the model of Section II is the yield on a noncallable long-term bond. Since noncallable long-term bonds do not exist, it is impossible to observe the current value of this variable. Hence it is necessary to construct a solution procedure that will use the observed market data on yields of newly issued callable bonds at any given time to infer simultaneously not only the unobservable uncertainty associated with expectations of future interest rates but also the unobservable interest rate which a noncallable bond would bear if issued at that time--and which equals the mean $E\left(\tilde{k}_{t}\right)$.

Three properties of the valuation model for callable bonds, all based on the requirement that the new-issue price equals 100 , facilitate the solution 
to this problem. First, if the standard deviation is $\sigma\left(\tilde{k}_{t}\right)=0$, the callable bond's coupon rate must equal the mean $E\left(\tilde{k}_{t}\right)$. Second, if $\sigma\left(\tilde{k}_{t}\right)>0$, the callable bond's coupon rate must exceed $E\left(\tilde{k}_{t}\right)$; the greater is $\sigma\left(\tilde{k}_{t}\right)$, the more the coupon rate must exceed $E\left(\tilde{k}_{t}\right)$. Third, this positive sensitivity to $\sigma\left(\tilde{k}_{t}\right)$ exhibited by the difference between the bond's coupon rate and $E\left(\hat{k}_{t}\right)$ is greater the sooner the bond becomes callable. Expressed compactly, these three properties are

$$
\begin{aligned}
s(0) & =0, \\
\frac{\partial s(\sigma)}{\partial \sigma} & >0, \\
\frac{\partial(\partial s(\sigma) / \partial \sigma)}{\partial D} & <0,
\end{aligned}
$$

where $s$ is the difference between the coupon rate and $E\left(\tilde{k}_{t}\right)$ which is required to render the bond's new-issue price equal to 100 , and $D$ is the length of the bond's call deferment as in Section II. That $s$ is a function of $\sigma\left(\tilde{k}_{t}\right)$, for given call features and interest rate expectations, follows directly from the callable bond valuation model as the illustrations presented in table 1 show.

Figure 3 indicates, by an example, the way in which properties (15)(17) of the callable bond valuation model facilitate its use to solve simultaneously for the standard deviation and the mean of the relevant expectations. The figure plots in $(E, \sigma)$ space, for a 5-year call-protected bond and

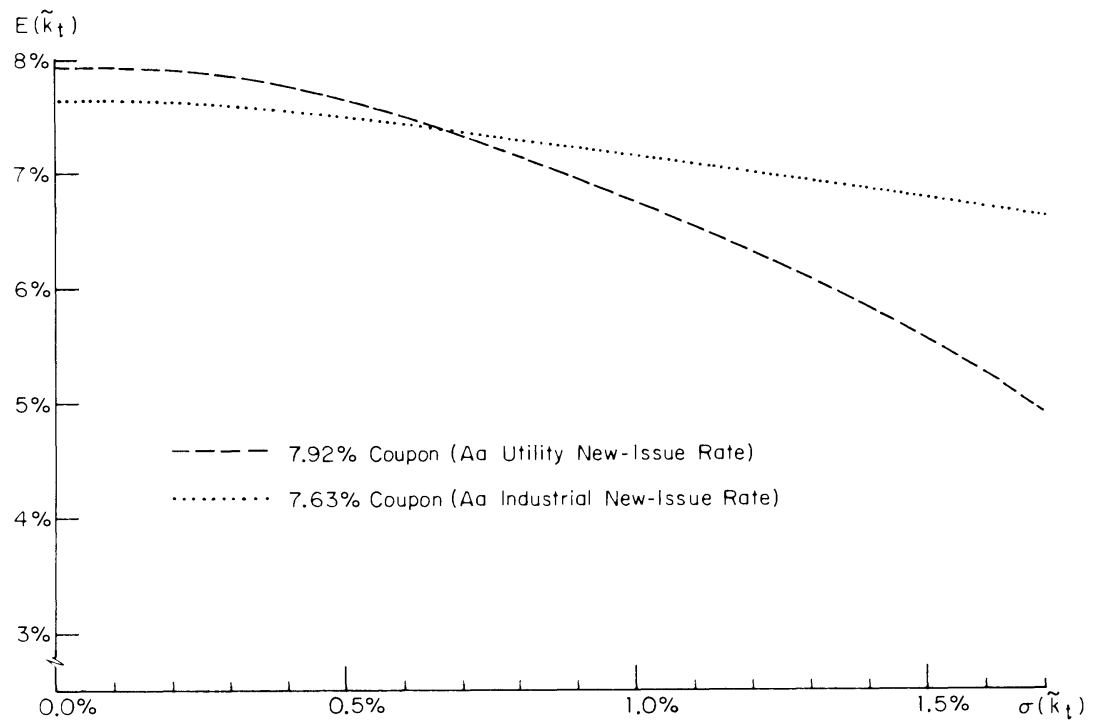

FIG. 3.-Example of solution method for interest rate uncertainty parameters 
for a 10-year call-protected bond with given respective coupon rates, ${ }^{30}$ those combinations of mean and standard deviation which are jointly consistent with a new-issue price of 100 for each bond. The application of the model underlying figure 3 is therefore precisely the reverse of that underlying the illustrations presented in table 1 . In those illustrations, the mean is given, and the role of the model is to solve for the particular coupon rate which is consistent with a new-issue price of 100 for each given standard deviation. By contrast, the coupon rate is given for each bond considered in figure 3 , and the role of the model is to solve for the particular mean which is consistent with a new-issue price of 100 for each given standard deviation. Since properties (15)-(17) pertain to the difference between the coupon rate and the mean, it is clear that the two solution procedures are equivalent.

From (15), a new-issue price of 100 for each bond would imply a mean equal to the bond's own coupon rate for a zero standard deviation; the respective intercepts of the two curves plotted in figure 3 reflect this property. From (16), both curves must be downward sloping in $(E, \sigma)$ space. From (17), the curve representing the bond with the shorter call deferment has a uniformly steeper downward slope than does the curve representing the bond with the longer call deferment. Since the curve representing the bond with the shorter call deferment also has the greater intercept, the two curves intersect at some point in $(E, \sigma)$ space. That point uniquely determines both the yield which the market would place on a long-term noncallable bond, which is also the mean $E\left(\tilde{k}_{t}\right)$, and the standard deviation $\sigma\left(\tilde{k}_{t}\right)$ associated with the market's expectations of future interest rates.

The solid lines in both panels of figure 2 plot the results of solving the bond-valuation model in this fashion, given the Salomon Brothers estimated new-issue yield series. ${ }^{31}$ The calculated mean $E\left(\tilde{k}_{t}\right)$, plotted in panel $a$, follows closely the pattern of new-issue yields on the callable bonds. Since the mean is also the implied yield on a long-term noncallable bond, it always remains below the corresponding yield on a callable bond. The calculated standard deviation $\sigma\left(\tilde{k}_{t}\right)$, plotted in panel $b$, analogously follows closely the utility-industrial yield spread; but the discrepancies between the two time series show clearly that the standard deviation is related to the overall level of new-issue yields as well. In 1969:IV, for example, the utility-industrial spread fell, while the standard deviation rose.

30 The specific coupon rates used in the example shown in the figure are those plotted in panel $a$ of fig. 1 for 1971:II.

${ }^{31}$ The computational procedure for deriving these results involves an iterative solution of the valuation model. As in the illustrations presented in Section II, the solutions shown in figs. 2 and 3 assume 25-year bonds with semiannual coupons and call prices declining linearly from a premium of 1 year's interest in the first half-year to no premium in the final half-year of the bond's term to maturity. 
Until the middle of 1974, these results indicate a standard deviation which varied between 50 and 75 basis points-on the whole, a reasonable value for the standard deviation of expectations of future long-term interest rates. ${ }^{32}$ The peak standard deviation during this interval occurred during 1970: II, contemporaneously with the Penn Central bankruptcy, the associated fears of market disorders, and the emergence of then-record longterm interest rates - again a reasonable result.

By mid-1974, however, the escalation of both short- and long-term interest rates to record high levels also brought with it a large increase in the utility-industrial new-issue yield spread. To the extent that this widening yield spread was related to the market's evaluation of the differences between the call provisions of these two kinds of bonds, the valuation model indicates a sharp increase in uncertainty about the course of future interest rates. While this result is again entirely plausible on a qualitative basis, even more than the usual degree of caution is appropriate in accepting the quantitative estimates of the standard deviation during this interval for two reasons. First, in the wake of the oil price increase and embargo in the winter of 1973-74, market participants may have feared that utility companies would face sufficient difficulties to increase the default risk associated with Aa utility bonds in comparison with Aa industrial bonds. ${ }^{33}$ Second, during late 1974 and early 1975 some few utility companies issued 10 -year call-protected bonds, so that the interpretation of the estimated new-issue yield series themselves is somewhat ambiguous. ${ }^{34}$ Nevertheless, an increase in the uncertainty associated with expectations of future interest rates, coming at a time of record high interest rates and record high price inflation, is a reasonable result. ${ }^{35}$

By late 1975, with the settling of the financial markets and partial abatement of price inflation, the standard deviation fell to below 1 percent once again. Since then, the standard deviation has varied narrowly between 75 and 100 basis points - somewhat above the range which prevailed before 1974 but well below the peak level during 1974 and early 1975.

A comparison of the overall pattern of the calculated standard deviation

\footnotetext{
32 The assumption of state independence of interest rate expectations leads the model to overstate the probability of refunding in the early years, and hence to overstate the value of the call option and to bias downward the calculated standard deviations. By contrast, the assumption of noncallability of the refinancing bond leads the model to understate the probability of refunding in the early years, and hence lends an offsetting upward bias to the calculated standard deviations.

${ }^{33}$ If this fear is the explanation for the widening utility-industrial yield spread, however, it is strange that the spread did not increase until 1974:II.

${ }^{34}$ At one point in 1974 Salomon Brothers' weekly publication, Bond Market Roundup, actually changed the heading of its estimated utility new-issue yield series to indicate 10 years of call protection; but the heading was changed back in early 1975 to indicate 5 years of call protection. Since early 1975 utility companies have again issued 5-year call-protected bonds almost exclusively.

${ }^{35}$ See Friedman (1975) for an analysis of the experience of the U.S. bond markets in 1974.
} 
and the observed new-issue yield series plotted in figure 2 suggests that, on the whole, increasing uncertainty has accompanied rising yields. Since this association appears to be far from regular, however, independent measures of the uncertainty associated with expectations of future interest rates provide useful information, in addition to observations of the currently prevailing yields themselves.

\section{Concluding Comments}

This paper uses a model of the valuation of bonds bearing call options, together with observed market yields on callable bonds, to assess interest rate uncertainty. A dynamic programming solution of the model simultaneously determines both the bond price and the issuer's optimal refunding strategy, given the relevant data describing the bond and the market's expectations of future interest rates. Application of the valuation model in reverse, for quarterly average data for 1969-76, generates a time series representing the uncertainty which the market associated with its expectations of future interest rates during this interval, given the then-prevailing yields on new issues of utility bonds and industrial bonds callable after 5 years and 10 years, respectively. This uncertainty, parameterized as the standard deviation of a truncated normal distribution, fluctuated between $\frac{1}{2}$ percent and $\frac{3}{4}$ percent between 1969 and early 1974, then rose to sharply higher levels from mid-1974 through mid-1975, and has fluctuated between $\frac{3}{4}$ percent and 1 percent since late 1975 .

A number of simplifying assumptions in the analysis of this paper represent interesting topics for further research. First, the use in the valuation model of a constant discounting factor mean for all future time periods is equivalent to the assumption of a flat term structure of interest rates. To the extent that yields on debts of different term to maturity differ, either because of nonstationary expectations or because of liquidity premiums, the individual coupon payments should be discounted by different factors. Since the actually prevailing term structure is typically fairly flat after the first several years, the approximation involved in assuming a totally flat term structure probably leads to significant overvaluation or undervaluation only for the first few coupon payments. Nevertheless, this assumption is merely convenient and is in no way a necessary element of the valuation model, so that allowing for any specified nonflat term structure would be straightforward. Similarly, allowing for any specified nonflat (probably increasing) standard deviation would also be straightforward.

Second, whereas both the hypothetical examples presented in Section II and the empirical work in Section III rely on normal distributions, using a different (perhaps asymmetrical) distribution to characterize expectations of future interest rates would be straightforward. 
Third, the limited empirical analysis presented in this paper is but one illustration of the form of application which is possible. In the case of timevariant expectations, the standard deviation series calculated in Section III would properly refer only to uncertainty with respect to the interval spanned by the sixth through tenth years after the point of measurement. This comparison is the only one currently possible on the basis of data on new issues of corporate bonds, given the conventional call option deferments; but using carefully selected data on seasoned bonds which have been outstanding for specified periods of time would permit drawing inferences about other subsets of the future as well.

It is interesting to note in this specific context that a further recent development in the U.S. corporate bond market, the advent of the intermediate-term note issue, has even further broadened the range of investors' selection with respect to call-option provisions-and has correspondingly further expanded the opportunities to learn about interest rate expectations. These intermediate-term notes are typically noncallable until maturity, and, especially for utility companies, the maturity is often identical to the period of deferment on exercise of the call option on the company's long-term bonds. A typical utility company, therefore, may issue not only 25-year debentures with 5 years of call protection but also 5 -year noncallable notes. This paper's analysis of the relative pricing of bonds with different call-protection time periods is also directly relevant to the relative pricing of intermediate-term notes versus long-term debentures. Turning around the usual interpretation of the call option, a longterm utility bond typically consists of a pure 5-year bond less an option to permit the issuer to extend the loan at his advantage for another period of years; the corresponding intermediate-term note is therefore simply equivalent to the pure bond part of this security, with no option attached. The appropriately calculated price (yield) difference between the longterm bond and the intermediate-term note may therefore provide a direct measure of the value of the extension option itself, and hence facilitate inferences about market participants' expectations of future interest rates.

Fourth, any estimates of interest rate uncertainty derived from bond yield comparisons, along the lines of this paper, would be more trustworthy if some effort were made to allow for factors apart from differential call deferments which may have an influence on the yield spread used to solve the model in reverse for the standard deviation. ${ }^{36}$

Finally, yet another potential object of future research would be to use regression analysis, with the calculated standard deviation series derived from the bond valuation model as the dependent variable, to test behavioral hypotheses about the determinants of the uncertainty which the market associates with its interest rate expectations.

\footnotetext{
${ }^{36}$ Fair and Malkiel (1971), e.g., have suggested a model relating movements in the utility-industrial yield spread to flow supplies of the two respective categories of bonds.
} 
In summary, the callable bond valuation model and its derivative approach to measuring interest rate uncertainty, as developed in this paper, provide the basis for a number of interesting further extensions of the model itself as well as additional and more refined empirical applications.

\section{References}

Bellman, Richard E. Dynamic Programming. Princeton, N.J.: Princeton Univ. Press, 1957.

Bellman, Richard E., and Dreyfus, Stuart E. Applied Dynamic Programming. Princeton, N.J.: Princeton Univ. Press, 1962.

$\rightarrow$ Black, Fischer, and Scholes, Myron. "The Pricing of Options and Corporate Liabilities." J.P.E. 81, no. 3 (May/June 1973): 637-54.

Bodie, Zvi, and Friedman, Benjamin M. "A Heterogeneous Expectations Model of the Value of Bonds Bearing Call Options.” Mimeographed. Harvard Univ., 1977.

Elton, Edwin J., and Gruber, Martin J. "The Economic Value of the Call Option." J. Finance 27 (September 1972): 891-901.

- Finance as a Dynamic Process. Englewood Cliffs, N.J.: Prentice-Hall, 1975.

Fair, Ray C., and Malkiel, Burton G. "The Determination of Yield Differentials between Debt Instruments of the Same Maturity." J. Money, Credit and Banking 3 (November 1971): 733-49.

Friedman, Benjamin M. "The Determination of Long-Term Interest Rates: Why Were Bond Yields So High in 1974?"' New England Econ. Rev. (May/June 1975), pp. 35-56.

Hess, Arleigh P., Jr., and Winn, Willis J. The Value of the Call Privilege. Philadelphia: Univ. Pennsylvania, 1962.

Hicks, John R. Value and Capital: An Inquiry into Some Fundamental Principles of Economic Theory. Oxford: Clarendon, 1939.

Jen, Frank C., and Wert, J. E. "The Effect of Call Risk on Corporate Bond Yields." J. Finance 22 (December 1967) : 637-51.

$\rightarrow$ Kalymon, Basil A. "Bond Refunding with Stochastic Interest Rates." Management Sci. 18 (November 1971): 171-83.

Karlin, Samuel. "Stochastic Models and Optimal Policy for Selling an Asset." In Studies in Applied Probability and Management Science, edited by Kenneth J. Arrow, Samuel Karlin, and Herbert Scarf. Stanford, Calif.: Stanford Univ. Press, 1962.

$\rightarrow$ Kraus, Alan. "The Bond Refunding Decision in an Efficient Market." J. Financial and Quantitative Analysis 8 (December 1973): 793-806.

$\rightarrow$ Lutz, Friedrich A. "The Structure of Interest Rates." Q.J.E. 54 (November 1940): 36-63.

Merton, Robert C. "On the Pricing of Corporate Debt: The Risk Structure of Interest Rates.” J. Finance 29 (May 1974): 449-70.

Modigliani, Franco, and Shiller, Robert J. "Inflation, Rational Expectations and the Term Structure of Interest Rates." Economica 40 (February 1973) : 12-43.

Nelson, Charles R. The Term Structure of Interest Rates. New York: Basic, 1972.

Ofer, Aharon R., and Taggart, Robert A., Jr. "Bond Refunding: A Clarifying Analysis." J. Finance 32 (March 1977) : 21-30.

$\rightarrow$ Pye, Gordon. "The Value of the Call Option on a Bond." J.P.E. 74 (April 1966): 200-205.

- "The Value of Call Deferment on a Bond: Some Empirical Results." J. Finance 22 (December 1967) : 623-36. 